\title{
Persistent left-sided superior vena cava
}

\author{
Jose Cuevas MD, Hawa Edriss MD
}

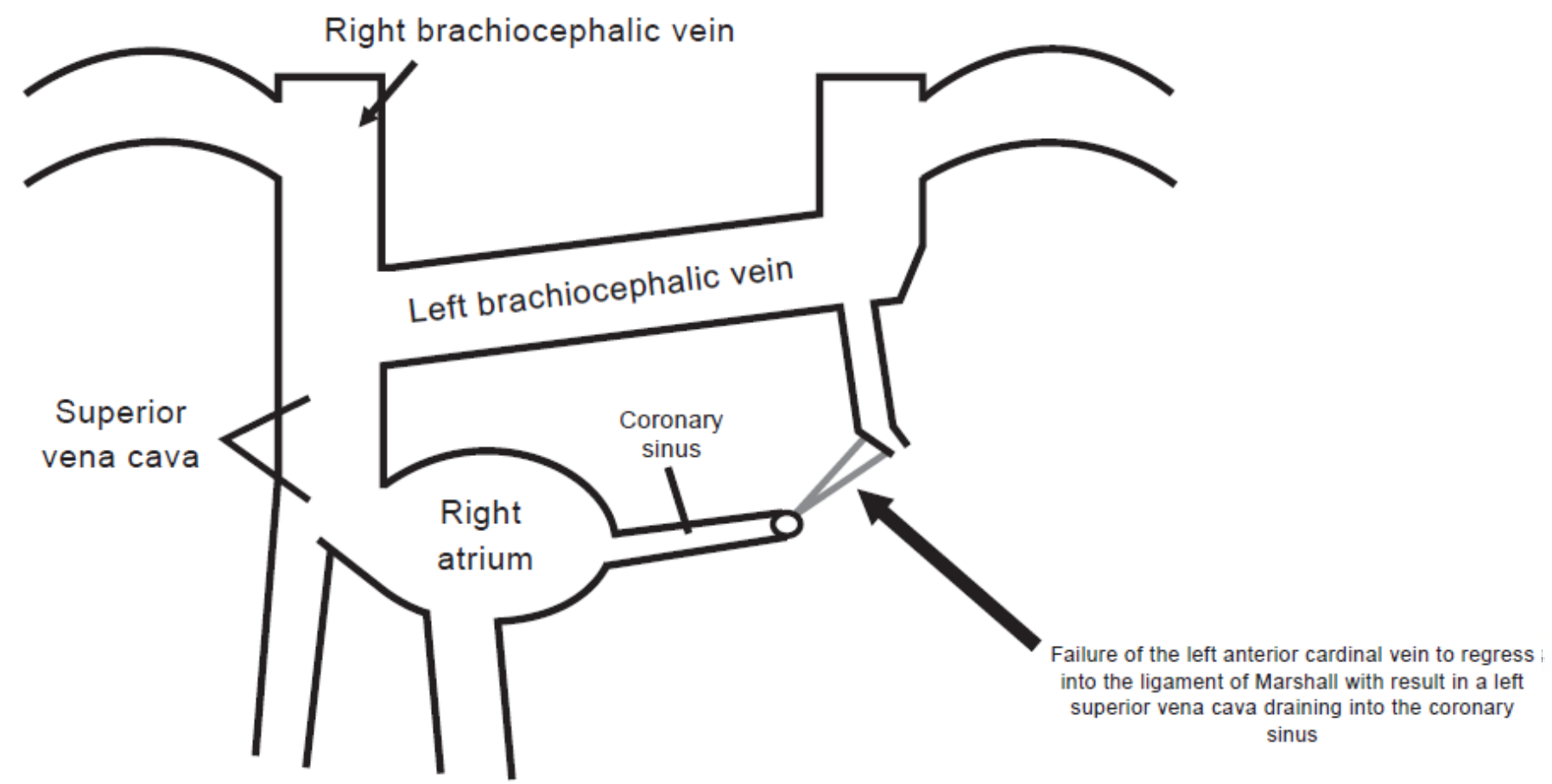

Figure 1. Schematic drawing of thoracic venous structures.

A persistent left-sided superior vena cava is the most common congenital anomaly present in thoracic venous anatomy. It is identified in $0.35 \%$ to $0.5 \%$ of the general population and in up to $10 \%$ of patients who have congenital cardiac malformations. ${ }^{1,2}$ It is commonly reported as an incidental finding during cardiovascular imaging, cardiothoracic surgery, and central venous catheter based procedures, which

Corresponding author: Jose Cuevas

Contact Information: Jose.cuevas@ttuhsc.edu DOI: 10.12746/swrccc 2015.0311.143 may include cardioverter-defibrillator implantation, electrophysiological procedures, and right heart catheterization. ${ }^{3,4}$ These procedures may present with complications when a left subclavian approach is used and result in unusual catheter positions, cannulation of the coronary sinus with subsequent perforation, and technical difficulties when attempting transvenous pacing or ICD implantation. ${ }^{5}$

During embryogenesis, the thoracic venous system consists of two major vessels, the right and left superior cardinal veins and the inferior cardinal vein, which return blood from the cranial and caudal 


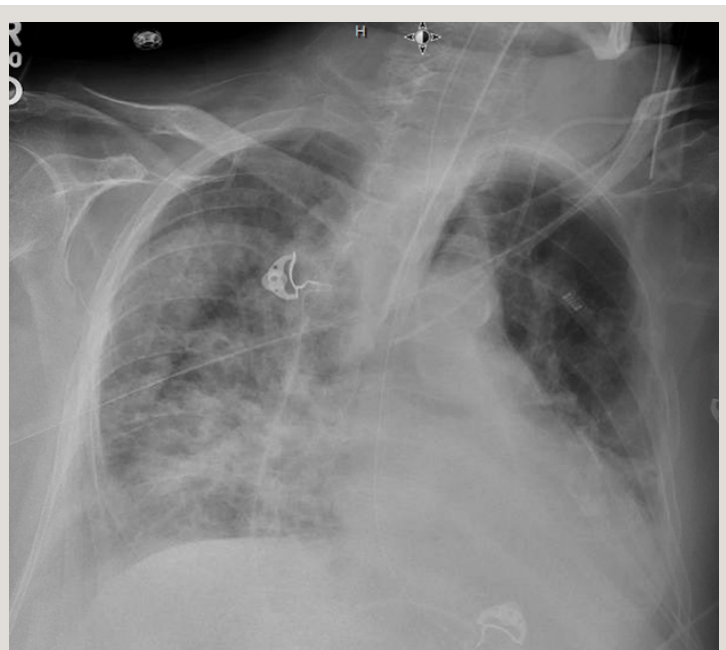

Figure 2. Portable A-P chest radiograph shows a catheter in the left superior vena cava entering the right atrium. A blood gas from this catheter had a $\mathrm{PaO}_{2}$ of $34 \mathrm{mmHg}$.

aspects of the embryo, respectively. During the 8th week of gestation, the right and left cardinal veins join to form the brachiocephalic vein, with the cephalic portion forming the internal jugular veins and the caudal portion forming the normal right-sided inferior vena cava. During this period, the left superior cardinal vein should regress and form the "ligament of Marshall". A left superior vena cava results from failure to obliterate the left superior cardinal vein. When this happens, the persistent left-sided superior vena cava will usually drain into the coronary sinus through the vein of Marshall. ${ }^{1,2}$ Most commonly, a persistent left-sided superior vena cava is present with a right-sided superior vena cava. In other cases, there may be regression of the right superior cardinal vein with subsequent absence of a right-sided superior vena cava.

Although generally asymptomatic and hemodynamically insignificant, due to its drainage directly into the coronary sinus, a left-sided superior vena cava may lead to serious complications when it is not identified during catheterization procedures. These complications include arrhythmia, cardiogenic shock, cardiac tamponade, and coronary sinus thrombosis after the introduction and manipulation of the catheter in the coronary sinus. ${ }^{6}$ It may also interfere with adequate administration of retrograde cardioplegia during cardiac surgery and increase the risk of arrhythmias, especially atrial fibrillation due to the arrhythmogenic potential of the ligament and vein of Marshall, which contain muscular fibers that are in direct contact with the coronary sinus. ${ }^{2}$

In conclusion, this uncommon thoracic venous system anomaly should be considered due to its potential complications during common procedures and its association with other congenital anomalies.

Author affiliations : Jose Cuevas and Hawa Edriss are residents in internal medicine at Texas Tech University Health Sciences Center in Lubbock, TX.

Submitted: 6/10/2015

Accepted: 6/30/2015

Reviewers: Kenneth Nugent MD

Conflict of Interest: None

Published electronically: 7/15/2015

\section{References}

1. Goyal SK, Punnam SR, Verma G, Ruberg FL. Persistent left superior vena cava: a case report and review of literature. Cardiovascular Ultrasound 2008; 6:50. doi:10.1186/1476-71206-50.

2. Irwin RB, Greaves M, Schmitt M. Left superior vena cava: revisited. Eur Heart J Cardiovasc Imaging 2012 Apr; 13(4):28491.

3. Siddiqui AM, Cao L-B, Movahed A. Side matters: An intriguing case of persistent left superior vena-cava. World Journal of Clinical Cases : WJCC 2013; 1(5):159-161.

4. Biffi M, Boriani G, Frabetti L, Bronzetti G, Branzi A. Left superior vena cava persistence in patients undergoing pacemaker or cardioverter-defibrillator implantation: a 10-year experience. Chest 2001 Jul; 120(1):139-44.

5. Ratliff HL, Yousufuddin M, Lieving WR, Watson BE, Malas A, Rosencrance G, McCowan RJ. Persistent left superior vena cava: case reports and clinical implications. Int J Cardiol 2006 Nov 10; 113(2):242-6.

6. Kurtoglu E, Cakin O, Akcay S, Akturk E, Korkmaz H. Persistent left superior vena cava draining into the coronary sinus: a case report. Cardiol Res 2011;2:249-252. 